\title{
Pulse Electroplating of Ultra-Fine Grained Au Films with High
}

\section{Compressive Strength}

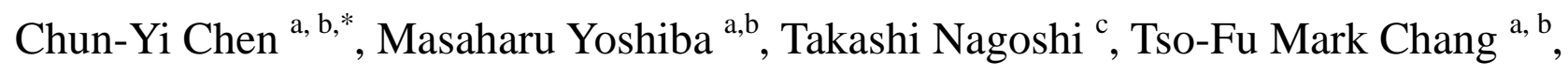
Daisuke Yamane $^{\text {a, b }}$, Katsuyuki Machida ${ }^{\text {a,b,d }}$, Kazuya Masu ${ }^{\text {a,b }}$, Masato Sone ${ }^{\text {a, b }}$

${ }^{a}$ Precision and Intelligence Laboratory, Tokyo Institute of Technology, Yokohama, 226-8503, Japan

${ }^{b}$ CREST, Japan Science and Technology Agency, Yokohama, 226-8503, Japan

${ }^{c}$ Advanced Manufacturing Research Institute, National Institute of Advanced Industrial Science and Technology, Ibaraki 305-8564, Japan

${ }^{d}$ NTT Advanced Technology Corporation, Atsugi, Kanagawa, 243-0124, Japan

${ }^{*}$ Corresponding author: Tel: +81-45-924-5631

E-mail: chen.c.ac@m.titech.ac.jp 


\begin{abstract}
Grain refinement, surface smoothening, and compressive strength enhancement of Au films were achieved by pulse electroplating using non-toxic sulfite-based electrolyte. The estimated grain size of the Au film prepared by pulse electroplating was $10.5 \mathrm{~nm}$, and it was much smaller than the grain size of the Au film prepared by constant-current electroplating, which was $22.8 \mathrm{~nm}$. This can be attributed to the increase in the nucleation rate during the on-time period. The mechanical strength of the Au films in micro-scale was also evaluated. The pulse electroplated Au micro-pillar acquired a high compressive strength of $800 \mathrm{MPa}$, and it was larger than the constant-current electroplated micro-pillar, which was 600MPa. The high strength is presumably due to the grain-boundary strengthening known as the Hall-Petch effect. The compression test also revealed that the pulse electroplated Au micro-pillar possesses better ductility and malleability than that fabricated by constant-current electroplating.
\end{abstract}

Keywords: Pulse current, Gold electroplating, Micro-compression test 


\section{Introduction}

Au materials fabricated by electroplating have been commonly used as contact materials for high reliability circuit boards, electrical connectors, relays, and micro- and nano-scale electronic components for many decades because of their high electrical conductivity, chemical stability, corrosion resistance, and ductility [1-5]. In recent years, Au has become a promising material for use as the movable structures and proof mass in micro-electrical-mechanical system (MEMS) accelerometer devices, because of its high density $\left(19.3 \times 10^{3} \mathrm{~kg} / \mathrm{m}^{3}\right.$ at $\left.298 \mathrm{~K}\right)$, which is about 10 times higher than that of silicon $\left(2.33 \times 10^{3} \mathrm{~kg} / \mathrm{m}^{3}\right.$ at $\left.298 \mathrm{~K}\right)$ [6]. However, Au is known to be a soft material. The mechanical strength becomes a concern in miniaturization of the MEMS device. Yield stress of bulk Au is reported to be 55 200MPa [7], and the strength can be increased to 550MPa when using specimens having sub-micro dimensions because of the size effect [8]. Decreasing grain size of the Au materials is expected to further enhance the mechanical properties according to the Hall-Petch relationship [9-10].

Pulse electroplating (PE) has been reported to be effective in fabricating Au materials with finer grains, higher uniformity, and lower porosity [11-12]. Also, it is possible to control the composition and the film thickness by regulating the pulse amplitude and width. Most importantly, an increase in the nuclei density could be achieved to obtain electroplated films with finer grains. On the other hand, the Vickers micro-hardness test is the most popular method for evaluating the mechanical properties of electroplated films. However, hardness results are often affected by the substrate. It cannot show the real strength of the electroplated materials, especially for films in mico-/nano-scale. Therefore, it is necessary to evaluate the micro-mechanical strength of Au electroplated films for practical applications in miniaturized devices.

In this study, the Au films prepared by PE with a sulfite-based electrolyte showed fewer defects, lower surface roughness, finer grain size, and denser texture when compared with the Au films prepared by the conventional constant-current electroplating (CE). The micro-mechanical properties of $\mathrm{Au}$ micro-pillars fabricated from the Au films prepared by PE and CE were evaluated by 
micro-compression tests. Some interesting information has been found in a webpage of the Russian Electroplating Society [13] (in Russian), where gold materials are claimed to have mechanical strength higher than $1 \mathrm{GPa}$. The results presented in the webpage could not be found in any refereed scientific journal, and the method by which the mechanical strength was evaluated is not clear. To the best of our knowledge, this is the first report on the micro-mechanical strength of pure Au materials fabricated by PE. Also, the electroplated pure Au film prepared by PE showed an ultra-high strength of 800MPa, which is the highest value reported for pure Au in the peer-reviewed literature.

\section{Experimental}

The Au electrolyte used in this study was a commercially available sulfite-based electrolyte provided by Matex Japan (Matex Gold NCA). The electrolyte contains $50 \mathrm{~g} / \mathrm{L}$ of $\mathrm{Na}_{2} \mathrm{SO}_{3}, 50 \mathrm{~g} / \mathrm{L}$ of $\left(\mathrm{NH}_{4}\right)_{2} \mathrm{SO}_{3}$, and $21.63 \mathrm{~g} / \mathrm{L}$ of $\mathrm{Na}_{3}\left[\mathrm{Au}\left(\mathrm{SO}_{3}\right)_{2}\right]$ with $\mathrm{pH}$ of 8.0 and $5 \%$ sodium gluconate. Cu plates and $\mathrm{Pt}$ plates were used as the cathode and anode, respectively. For the PE, the pulse current $\left(\mathrm{I}_{\mathrm{on}}\right)$ was $10 \mathrm{~mA} / \mathrm{cm}^{2}$, and the off-time current $\left(\mathrm{I}_{\text {off }}\right)$ was $0 \mathrm{~mA} / \mathrm{cm}^{2}$. The on-time $\left(\mathrm{T}_{\text {on }}\right)$ and the off-time $\left(\mathrm{T}_{\text {off }}\right)$ of the $\mathrm{PE}$ were fixed at $10 \mathrm{~ms}$ as the optimized parameter. The reaction temperature was $40^{\circ} \mathrm{C}$ for both $\mathrm{PE}$ and CE. For the CE, the current density was fixed at $5 \mathrm{~mA} / \mathrm{cm}^{2}$, which is the same as the average current density of the PE. A gold film was electroplated using a cyanide-based electrolyte containing 230g/L of di-ammonium hydrogen citrate, $85 \mathrm{~g} / \mathrm{L}$ of $\mathrm{KCN}$, and $14.63 \mathrm{~g} / \mathrm{L}$ of $\mathrm{K}\left[\mathrm{Au}(\mathrm{CN})_{2}\right]$ with $\mathrm{pH}$ of 5.0 also provided by Matex Japan (Matex Gold BOG-10) to serve as the comparison reference. The Au film was electroplated on a Pt substrate. The current density used was $4 \mathrm{~mA} / \mathrm{cm}^{2}$, and the temperature was $60^{\circ} \mathrm{C}$.

After the electroplating, micro-pillars were made from the Au films by focused ion beam (FIB, FB2100, Hitachi) milling. The dimensions of the fabricated pillars were $10 \mu \mathrm{m} \times 10 \mu \mathrm{m} \times 20 \mu \mathrm{m}$. The compression tests were carried out using a test machine specially designed for micro-sized specimens equipped with a flat-ended diamond indenter at a constant displacement of $0.1 \mu \mathrm{m} / \mathrm{s}$. Observation of the specimens before and after the compression test was conducted using the scanning ion microscope (SIM) 
equipped with the FIB. The morphology of the Au films was examined by an atomic force microscope (AFM, XE-100, Park System). The crystallographic structures were investigated by an X-ray diffractometer (XRD, Ultima IV, Rigaku). The X-ray was operated at 40kV and 40mA. Average grain size was calculated using the Scherrer equation.

\section{Results and discussion}

Figure 1 shows the AFM micrographs of the Au films. The Au film fabricated by the cyanide-based electrolyte (CE-Cy-F) had hill-like bumps morphology and the roughest surface, as shown in Figure 1(a), and the surface roughness $\left(R_{a}\right)$ was $117.09 \mathrm{~nm}$. The Au film prepared by CE with the sulfite-based electrolyte (CE-Su-F) showed irregular small dome-shaped bumps with a height of ca. $0.2-0.25 \mu \mathrm{m}$, as shown in Figure 1(b). On the other hand, the Au film fabricated by PE with the sulfite-based electrolyte (PE-Su-F) had a smooth and defect-free surface, as shown in Figure 1(c). For the CE-Su-F, the surface roughness was $32.5 \mathrm{~nm}$, whereas it was only $10.7 \mathrm{~nm}$ for the PE-Su-F. The smooth surface achieved by PE was attributed to the enhanced desorption of the hydrogen gas bubbles during the off-time of the PE, because the defects are suggested to be caused mainly by the hydrogen gas bubbles during plating.

Figure 2 shows the XRD patterns of the Au films. All XRD patterns exhibit four peaks corresponding to the (111), (200), (220), and (311) planes of metallic face-centered cubic gold (JCPDS No.04-0784). The XRD results are similar to the work reported by Bozzini et al. [14]. Unlike the reference CE-Cy-F, the Au films fabricated with the sulfite-based electrolyte showed intense (111) orientation. It was reported that the surface energy of the (111) crystal growth orientation is the lowest when compared with the other crystal orientation such as (100) and (110) planes [15]. Moreover, the XRD peaks of the PE-Su-F were broader than those by the CE. The estimated grain size of the PE-Su-F was $10.5 \mathrm{~nm}$, which was much smaller than the grain size of 22.8 and 17.6 for the CE-Su-F and the 
CE-Cy-F, respectively. The grain refinement effect can be attributed to the higher pulse current density and nucleation rate during the on-time.

In summary, the AFM micrographs and XRD patterns indicate that smooth and defect-free Au film with an ultra-fine grain size of $10.5 \mathrm{~nm}$ can be achieved by the optimized parameters of the PE. The grain size is smaller than the values reported in previous studies [16-18]. For the optimized PE parameters, the pulse current is $10 \mathrm{~mA} / \mathrm{cm}^{2}$ and the off-time current is $0 \mathrm{~mA} / \mathrm{cm}^{2}$. On-time and off-time of the PE are both $10 \mathrm{~ms}$.

The microstructure of the pillars before and after the compression test and the deformation behavior were observed from the SIM images shown in Figure 3. The ion channeling contrast shown in the SIM images indicates orientation changes of the grains on the sample surface. An Au pillar was fabricated from the CE-Cy-F to act as a comparison, and the result is shown in Figure 3(a) and (b). White and gray irregular strip-patterns in several $\mu \mathrm{m}$ order were observed on both of the top and side-wall surfaces, and these patterns may be attributed to the columnar textures with a direction perpendicular to the substrate/electrolyte interface. Cracks shown in Figure 3(b) indicate brittle fractures along the texture boundary, which suggest the brittle nature of the texture boundary. The grain size obtained from XRD was $17.6 \mathrm{~nm}$, which is far smaller than the size of the patterns observed in the SIM image. While the contrast of the SIM image represents orientation against the beam direction, the boundaries observed in Figure 3(a) and (b) should be texture boundaries instead of grain boundaries. Camouflage pattern of the grain/structure was observed on the surface of the Au pillar prepared from the CE-Su-F, as shown in the SIM image shown in Figure 3(c). The Au pillar showed broad shear crossing from the top front to the bottom after ca. 10\% of deformation, as shown in Figure 3(d), which is similar to the deformation of electrodeposited nanocrystalline Ni [19]. In Figure 3(e), there is no obvious grain/texture boundary on the Au pillar, which is consistent with the $\mathrm{XRD}$ result that fine grains of $10.5 \mathrm{~nm}$ were caused by the PE since the SIM could not identify boundaries finer than ca. $1 \mu \mathrm{m}$. The ductile deformation shown in Figure 3(f) was attributed to the intrinsic property of ultra-fine or 
nanocrystalline materials during the compressive deformation [20]. Although the grain size was different between the micro-pillars fabricated from the CE-Su-F and the PE-Su-F, the deformation behaviors were similar as shown in Figure 3(d) and (f).

Figure 4(a) shows compressive engineering stress-strain curves of the Au micro-pillars. Deformation behavior of the pillar prepared from the CE-Cy-F was different from the pillars prepared from the CE-Su-F and the PE-Su-F. Yield drop observed in the pillar prepared from the CE-Cy-F may correspond to the cracks observed in Figure 3(b). The cracks are suggested to be caused by the impurities derived from the bath, which lead to a decrease in the adhesion between the texture boundary. The pillars prepared from the CE-Su-F and the PE-Su-F showed parabolic hardening generally observed in polycrystalline samples. Notable work hardening observed in the pillar prepared from the PE-Su-F could be a consequence of the reduction in defects by the PE. A summary of the strengths obtained from this work and from the literature is shown in Figure 4(b). The strengths obtained in this work followed the Hall-Petch relationships and reached 800MPa. To the best of our knowledge a compressive strength of $800 \mathrm{MPa}$ is the highest value reported for electrodeposited pure Au when compared with the literatures [7,8,21,22]. Also, the Au film prepared by PE had large work hardening which indicates high ductility and malleability of the material.

\section{Conclusions}

Pulse electroplating and a sulfite-based electrolyte were used in fabrication of Au films. The surface of the PE Au film possessed fewer defects, lower roughness, smaller grain size, and denser texture when compared with the Au film prepared by CE. The grain size of the PE-Su-F was estimated to be $10.4 \mathrm{~nm}$, and the compressive strength was $800 \mathrm{MPa}$ for the specimen having dimensions of $10 \mu \mathrm{m} \times 10 \mu \mathrm{m} \times 20 \mu \mathrm{m}$. The grain size is much smaller, and the compressive strength obtained is much higher than the values reported in other studies. The high strength is suggested to be due to the grain-boundary strengthening mechanism known as the Hall-Petch effect. The results demonstrated that 
the pulse electroplating method and the sulfite-based electrolyte are promising for applications in miniaturization of electronic devices.

\section{Acknowledgment}

This work was supported by the Grant-in-Aid for CREST project from the JST and the JSPS KAKENHI Grant Number 26220907. 


\section{References}

[1] N. Togasaki, Y. Okinaka, T. Homma, T. Osaka, Preparation and characterization of electroplated amorphous gold-nickel alloy from electrical contact applications, Electrochim. Acta 51 (2005) 882-887.

[2] M. Kato, K. Senda, Y. Musha, J. Sasano, Y. Okinaka, Electrodeposition of amorphous gold alloy films, T. Osaka, Electrochim. Acta 53 (2007) 11-15.

[3] N. Yamachika, Y. Musha, J. Sasano, K. Senda, M. Kato, Y. Okinaka, T. Osaka, "Electrodeposition of amorphous Au-Ni alloy film, Electrochim. Acta 53 (2008) 4520-4527.

[4] E. Brun, F. Durut, R. Botrel, M. Theobald, O. Legaie, I. Popa, V. Vignal, Influence of the electrochemical parameters on the properties of electroplated $\mathrm{Au}-\mathrm{Cu}$ alloys, J. Electrochem. Soc. 158 (2011) D223-D227.

[5] H. Homma, Plating technology for electronics packaging, Electrochimica Acta 47 (2001) 75-84.

[6] D. Yamane, T. Konishi, T. Matsushima, K. Machida, H. Toshiyoshi, K. Masu, Design of sub-1g microelectromechanical systems accelerometers, Appl. Phys. Lett. 104 (2014) 074102.

[7] J. R. Greer, W. C. Oliver, W. D. Nix, Size dependence of mechanical properties of gold at the micron scale in the absence of strain gradients, Acta Materialia 53 (2005) 1821-1830.

[8] H.D. Espinosa, B.C. Prorok, B. Peng, Plasticity size effects in free-standing submicron polycrysta lline FCC films subjected to pure tension, J. Mech. Phys. Solid 52 (2004) 667-689.

[9] E.O Hall, The deformation and ageing of mild steel: II characteristics of the Lüders deformation, Proc. Phys. Soc. London B 64 (1951) 747-753.

[10] N. J. Petch, The cleavage strength of polycrystals, J. Iron Steel Inst. 174 (1953) 25-28.

[11] J. Horkens, L. T. Romankiw, Pulsed potentiostatic deposition of gold from solutions of the Au (I) sulfite complex, J. Electrochem. Soc. 124 (1977) 1499-1505.

[12] A. Ruffoni, D. Landolt, Pulse-plating of Au-Cu-Cd alloys: II. theoretical modelling of alloy 
composition, Electrochim. Acta 33 (1988) 1281-1289.

[13] Russian

Electroplating

Society.

http://www.galvanicrus.ru/lit/articles/cyan-free_aurum_plating_electrolytes.php

(accessed 16.03.16).

[14] B. Bozzini, A. Fanigliulo, M. Serra, Electrodeposition of star-shaped gold crystallites, J. Cryst. Growth 231 (2001) 589-598.

[15] D. Udler, D. N., Seidman, Grain boundary and surface energies of fcc metals, Phy. Review B 54 (1996) R11133-R11136.

[16] Y. Lee, S. K. Ahn, Y. Roh, Comparison of nanometer-scale gold structures electrodeposited on Au and Pt seed electrode, Surf. Coating Tech. 193 (2005) 137-141.

[17] M. S. Chandrasekar, M. Pushpavanam, Pulse and pulse reverse plating conceptual, advantages and applications, Electrochim. Acta 53 (2008) 3313-3322.

[18] O. Yevtushenko, H. Natter, R. Hempelmann, Grain-growth kinetics of nanostructured gold, Thin Solid Films 515 (2006) 353-356.

[19] T. Nagoshi, M. Mutoh, T.-F. M. Chang, T. Sato, M. Sone, Sample size effect of electrodeposited nickel with sub-10nm grain size, Mater. Lett. 117 (2014) 256-259.

[20] D. Jia, K.T. Ramesh, E. Ma, Effects of nanocrystalline and ultrafine grain sizes on constitutive behavior and shear bands in iron, Acta Mater. 51 (2003) 3495-3509.

[21] Z. Gan, Y. He, D. Liu, B. Zhang, L. Shen, Hall-Petch effect and strain gradient effect in the torsion of thin gold wires, Scripta Materialia 87 (2014) 41-44.

[22] R. D. Emery, G. L. Povirk, Tensile behavior of free-standing gold films. Part II. Fine-grained films, Acta Materialia 51 (2003) 2079-2087. 


\section{Figures}

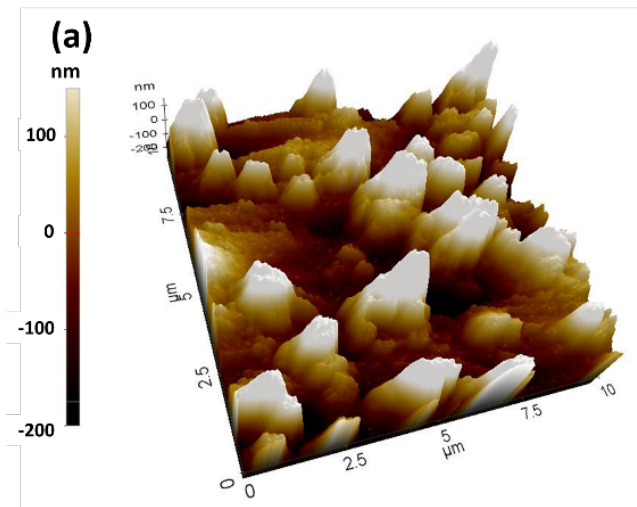

(b)

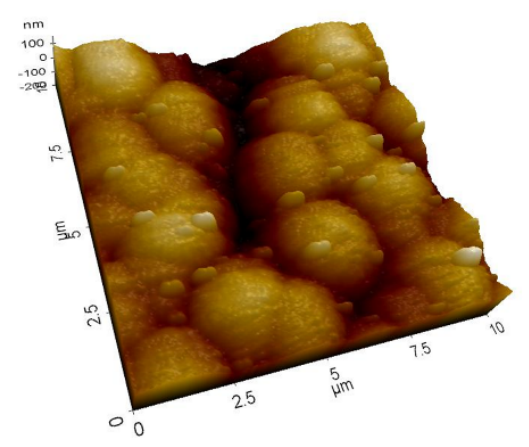

(c)

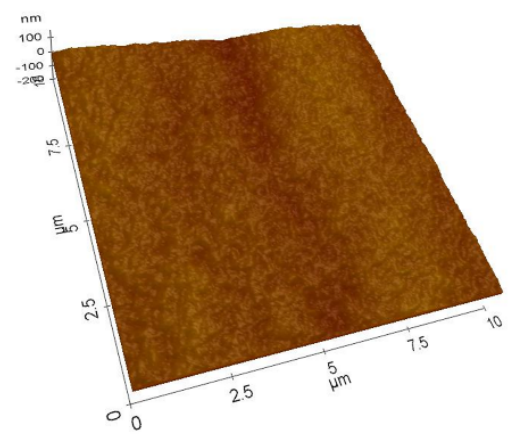

Figure.1 AFM micrographs of (a) the Au film surface prepared by the CE with the cyanide-based electrolyte, (b) the Au film surface prepared by the CE and (c) the PE with the sulfite-based electrolyte. 


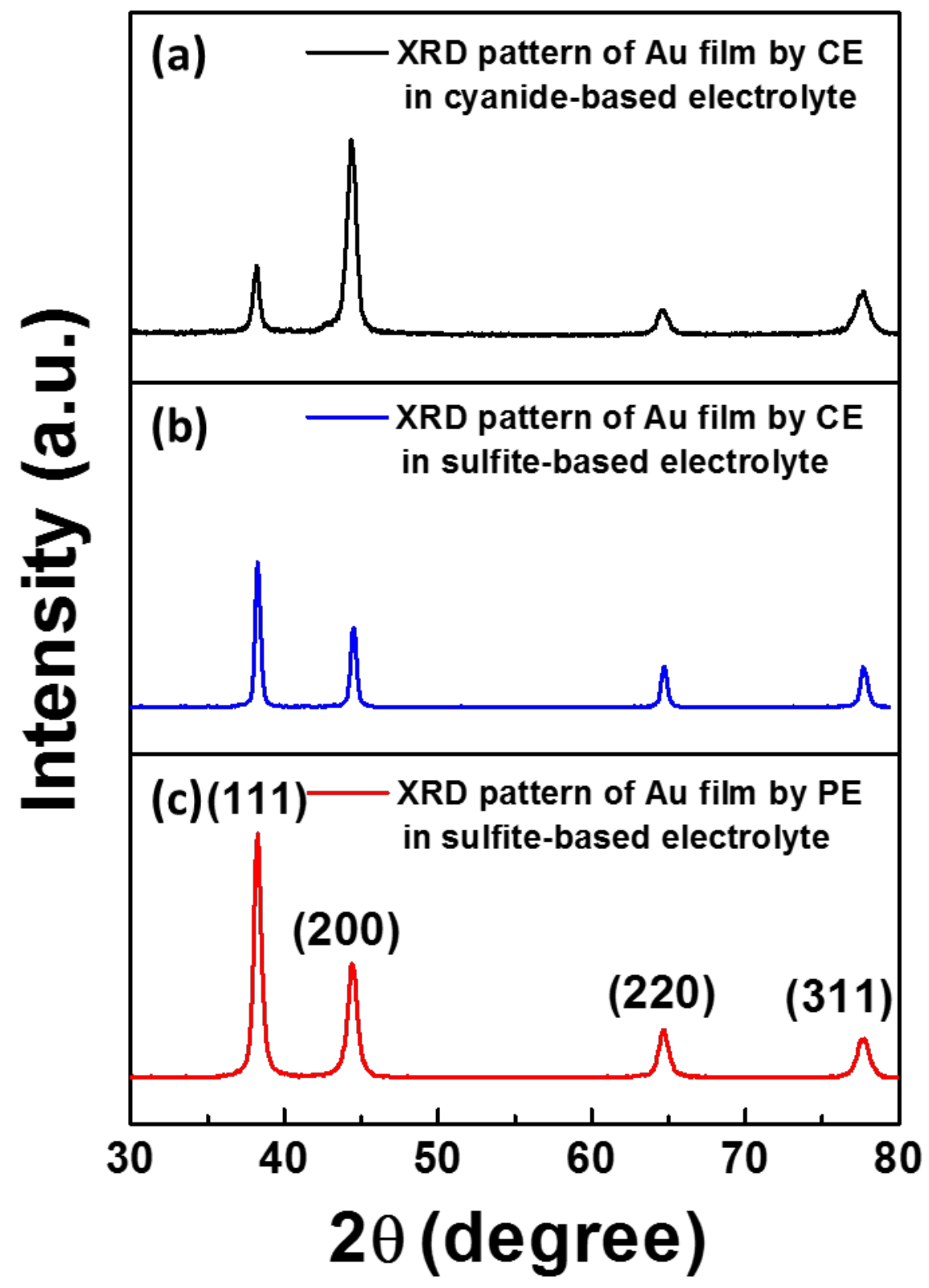

Figure.2 X-ray diffraction patterns of (a) the Au film prepared by the CE with the cyanide-based electrolyte, (b) the Au film prepared by the CE and (c) the PE with the sulfite-based electrolyte. 

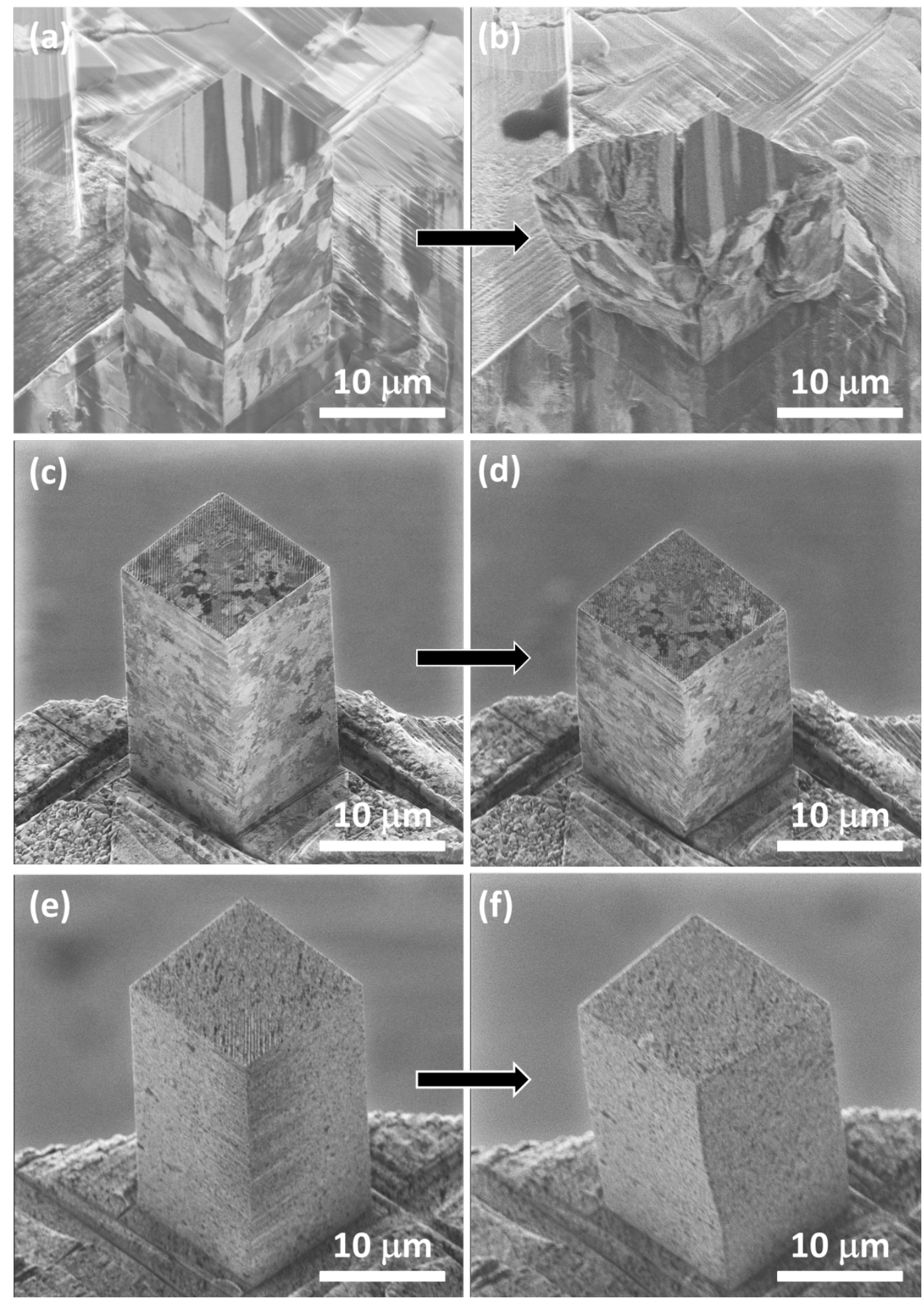

Figure. 3 SIM images of the (a) as-fabricated and (b) deformed Au pillars fabricated from the CE with the cyanide-based electrolyte, the (c) as-fabricated and (d) deformed Au pillars fabricated from the CE with the sulfite-based electrolyte, and the (e) as-fabricated and (f) deformed Au pillars fabricated from the PE with the sulfite-based electrolyte. 

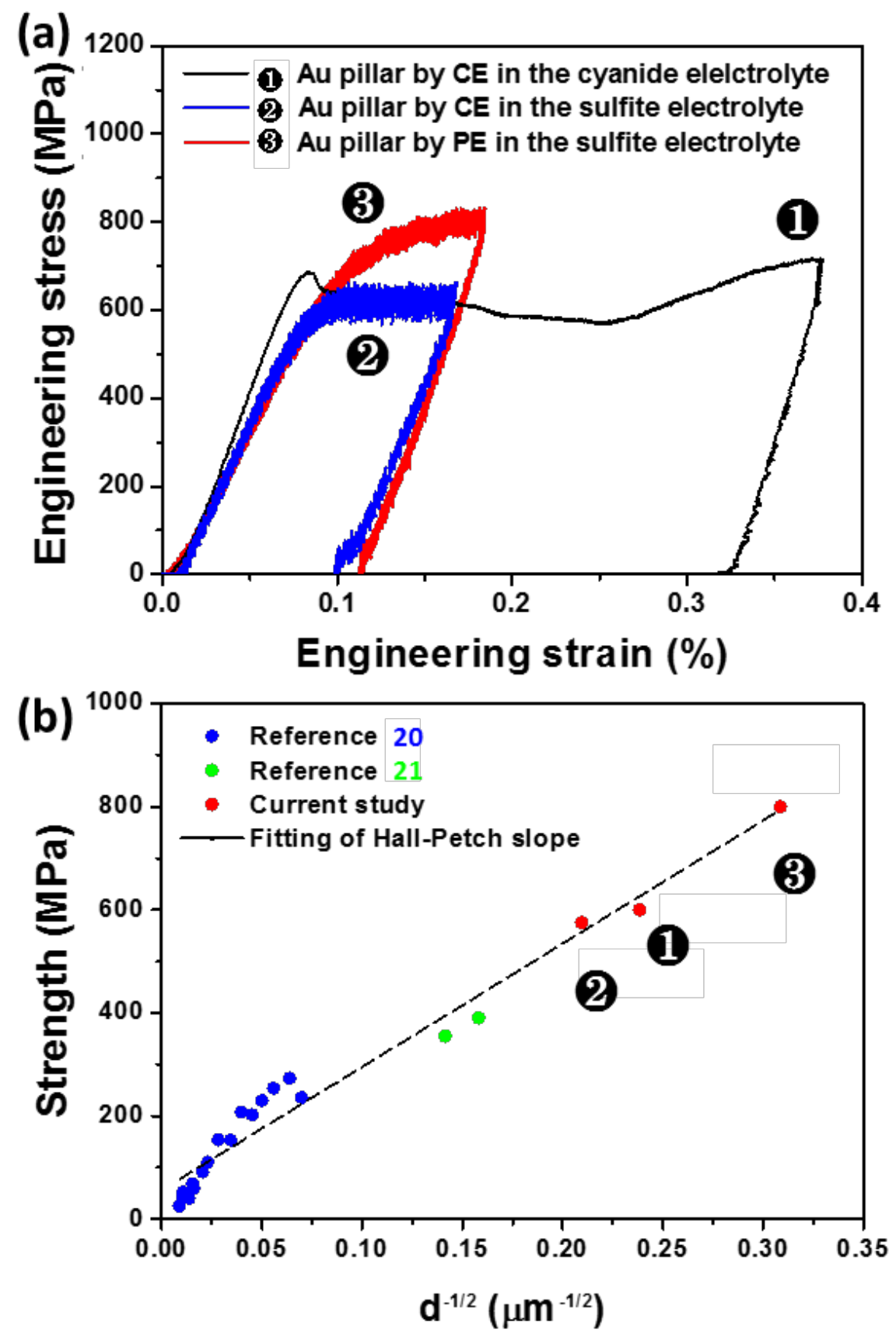

Figure. 4(a) Engineering stress-strain curves obtained from the micro-compression test of the Au micro-pillars and (b) Hall-Petch plot of polycrystalline Au pillars. 
